\title{
A STUDY ON ANALYSIS OF VALIDITY OF LATERAL PLACENTAL LOCATION IN PREDICTION OF PREECLAMPSIA
}

\author{
Abiramavalli Kannamani ${ }^{1}$, Dhivya Narasimhan ${ }^{2}$
}

${ }^{1}$ Senior Assistant Professor, Department of Obstetrics and Gynaecology, Institute of Obstetrics and Gynaecology, Egmore, Chennai. ${ }^{2}$ Consultant Obstetrician and Gynaecologist, Billroth Hospitals, Chennai.

\section{ABSTRACT}

\section{BACKGROUND}

Aim of the study is to analyse whether placental location as determined by ultrasound at 18-24 weeks can predict the subsequent development of preeclampsia.

\section{MATERIALS AND METHODS}

This study was conducted in 300 women at the Department of Obstetrics and Gynaecology for a period of one year. The location of placenta was determined by ultrasound at 18-24 weeks of gestational age in the study population. The placental position was being classified as central, right/left. Prospectively case group and control group were followed up and looked for the occurrence of hypertension.

\section{RESULTS}

$50 \%$ of mothers were in the 20-25 years age group. Preeclampsia was high between 20-25 years. The incidence of preeclampsia in primigravida was $81 \%$ and multigravida was $19 \%$. Among the patients with centrally located placenta, the incidence of preeclampsia was $19.1 \%$ whereas in the case group which had laterally located placenta the incidence of preeclampsia was $80.9 \%$ with a statistically significant $p$ value of 0.01 . This screening test has a very high negative predictive value of $96.4 \%$ and a sensitivity of $81 \%$. Hence, routine ultrasound and placental position screening can be used as a predictor for the development of hypertensive disorders of pregnancy.

\section{CONCLUSION}

This study shows that placental position as determined by ultrasound between 18-24 weeks of gestation is an excellent screening tool for the prediction of preeclampsia among numerous screening tests with a very high sensitivity. This test is simple, easy to perform, inexpensive and noninvasive. Lateral placentation helps to identify the population who are at a greater risk to be included in the primary prevention programs.

\section{KEYWORDS}

Preeclampsia, Lateral Placentation.

HOW TO CITE THIS ARTICLE: Kannamani A, Narasimhan D. A study on analysis of validity of lateral placental location in prediction of preeclampsia. J. Evolution Med. Dent. Sci. 2017;6(18):1401-1403, DOI: 10.14260/Jemds/2017/306

\section{BACKGROUND}

Hypertensive disorders represent the most common medical disorders complicating pregnancy. It comprises up to 7-10\% of pregnancies. ${ }^{1}$ Preeclampsia and eclampsia contribute up to $12 \%$ of all maternal deaths in the developing countries (WHO 1999). Infants of women with severe pregnancy-induced hypertension have 5-fold increase in mortality compared to infants of normotensive women.

Preeclampsia is a multi-organ disorder and usually recognised by new onset of hypertension and proteinuria appearing in the latter half of pregnancy. Gestational hypertension, preeclampsia, eclampsia, majority of these conditions are preventable.

This has led to the interest in screening. Screening the substantial segments of population in search for disease at its earlier stages is a logistic extension of the role of preventive

Financial or Other, Competing Interest: None.

Submission 30-11-2016, Peer Review 14-01-2017,

Acceptance 20-01-2017, Published 02-03-2017.

Corresponding Author:

Dr. Abiramavalli Kannamani,

Plot No. 247, Eswaran Nagar,

Veppampattu, Thiruvallur-602024.

E-mail: rajangamin@yahoo.com

DOI: $10.14260 /$ jemds $/ 2017 / 306$ medicine. If we wish to prevent such disorder, we must seek ways of preventing or ameliorating the disease process. In preventing the disorder, the most important factor is timely prediction of its occurrence.

Noninvasive Doppler velocimetric studies of the uterine arteries in the second trimester reveal that the abnormal waveforms indicating defective uterine perfusion is primarily a consequence of placental implantation when one uterine artery is the dominant supply of the intervillous flow. ${ }^{2}$ The placenta is located laterally in majority of patients with abnormal flow velocity waveforms. ${ }^{3}$ In the light of these observations, we designed a prospective study to find out whether the lateral location of placenta as seen by ultrasound at 18-24 weeks of gestation can be used to predict the development of preeclampsia.

\section{Aim of the Study}

To analyse whether placental location as determined by ultrasound at 18-24 weeks can predict the subsequent development of preeclampsia.

\section{MATERIALS AND METHODS}

The study was conducted at Department of Obstetrics and Gynaecology, Government RSRM Lying-in Hospital, Chennai. 
Study Period- One year.

Study Design- Prospective Study.

300 pregnant women attending the antenatal clinic were registered in this study. Only those pregnant women who could be followed up to term and were planning delivery at our hospital were included in this study.

The location of placenta was determined by ultrasound at 18-24 weeks in all 300 women. The placenta was classified as central when it was equally distributed between the right and the left side of the uterus irrespective of anterior, posterior or fundal position. When $75 \%$ or more of the placental mass was to one side of the midline it was classified as unilateral right or left placenta. The end point of the study was to follow these patients and watch for the occurrence of hypertension as per the ACOG criteria.

\section{Patient Selection Criteria Inclusion Criteria}

1. Gestational age between 18-24 weeks.

2. Women who intend to have their deliveries in our hospital.

\section{Exclusion Criteria}

1. History of chronic hypertension.

2. History of Diabetes Mellitus.

3. History of renal disease.

4. BP > 140/90 mmHg.

5. Evidence of proteinuria by dipstick.

\section{Methodology}

1. Written informed consent was obtained.

2. No dietary alterations were recommended.

3. Detailed history was taken.

4. Complete systemic examination and an obstetric examination were done.

5. The location of the placenta was determined by USG at 1824 weeks in all the 300 women. The placenta is classified as central when it is equally distributed between the right and the left side of the uterus irrespective of anterior, posterior or fundal position.

6. When $75 \%$ or more of the placental mass was to one side of the midline it was classified as unilateral right or left placenta.

7. Followed up with routine antenatal visits for signs and symptoms of preeclampsia by routine examination of BP, serial weight, oedema and investigations for preeclampsia when required and results were tabulated.

8. The mode of delivery and foetal outcome was noted.

\section{RESULTS}

Majority of the patients (152) fell in the age group between 2025 constituting about $50.7 \%$. 21\% of patients (63) fell in the age group $<20$ years. Another $21 \%$ of patients (63) fell in the age group between $25-30,7.3 \%$ of patients (22) were more than 30 years old.

\begin{tabular}{|c|c|c|c|}
\hline Parity & Total & Preeclampsia & $\%$ \\
\hline Primi & 222 & 34 & 81 \\
\hline Multigravida & $\mathbf{7 8}$ & 8 & 19 \\
\hline \multicolumn{3}{|r|}{ Table 1. Distribution of Patients with } \\
Preeclampsia According to Parity \\
\hline
\end{tabular}

\begin{tabular}{|c|c|c|}
\hline Placental Position & Hypertensive & Normotensive \\
\hline Central (228) & $8(19.1) \%$ & $220(85.2 \%)$ \\
\hline Lateral (72) & $34(80.9 \%)$ & $38(14.8 \%)$ \\
\hline \multicolumn{3}{|c|}{$\begin{array}{c}\text { Table 2. Relationship of Placental Position } \\
\text { and Development of Preeclampsia }\end{array}$} \\
\hline
\end{tabular}

\begin{tabular}{|c|c|}
\hline Gestational Age in Weeks. & No. of Patients \\
\hline $26-28$ & $\mathbf{1}$ \\
\hline $29-31$ & $\mathbf{3}$ \\
\hline $32-34$ & $\mathbf{6}$ \\
\hline $35-37$ & $\mathbf{1 5}$ \\
\hline $38-40$ & $\mathbf{1 7}$ \\
\hline$>40$ & NIL \\
\hline \multicolumn{2}{|c|}{$\begin{array}{c}\text { Table 3. Gestational Age wise Distribution } \\
\text { of Development of Preeclampsia }\end{array}$} \\
\hline
\end{tabular}

\begin{tabular}{|c|c|}
\hline Type of Preeclampsia & Study Group \\
\hline Mild Preeclampsia & 38 \\
\hline Severe Preeclampsia & 4 \\
\hline \multicolumn{2}{|c|}{ Table 4. Distribution of Patients } \\
According to Severity of Preeclampsia \\
\hline
\end{tabular}

Predictive Value of Placental Position in Predicting Preeclampsia

Sensitivity $81 \%$.

Specificity $85.3 \%$.

Positive Predictive Value $47.2 \%$.

Negative Predictive Value 96.4\%.

\section{DISCUSSION}

Preeclampsia is a complex clinical syndrome involving multiple organ systems and still remains the principal cause of maternal and perinatal mortality and morbidity. 4,5 It has been shown that in humans, both uterine arteries have a significant number of branches and each supply the corresponding side of the uterus. Although anastomoses between the two uterine arteries exist, there is no proof that these are functional. 6 When the placenta is laterally located, the uterine artery close to the placenta has lower resistance than the one opposite from it. In patients with centrally located placenta, both uterine arteries demonstrate similar resistance. When the placenta is centrally located, the uteroplacental blood flow needs are met by equal contribution from both uterine arteries. However, when the placenta is laterally located, in the majority of the patients, the uteroplacental blood flow needs are to be met primarily by one of the uterine artery, with some contribution by the other uterine artery via collateral circulation. ${ }^{7}$ This degree of collateral circulation; however, may not be the same in all patients and deficient contribution may facilitate the development of preeclampsia, IUGR or both. The existence of major vascular anastomoses in some patients may explain the normal uterine flow velocity waveform and absence of preeclampsia and IUGR despite the presence of a unilateral placenta. 8 In normal pregnancies, the spiral arterioles that supply the placental bed undergo trophoblast induced conversion to uteroplacental arterioles. The significance of normal placentation for this cytotrophoblastic invasion is high and the cytotrophoblasts fail to adopt a vascular adhesion phenotype in preeclampsia.6,9 In preeclampsia conversion of the spiral arterioles is 
incomplete. ${ }^{10}$ It involves only the subplacental venules. If there were no functional anastomoses between right and left uterine arteries, in cases with unilaterally located placentas, one would expect the ipsilateral uterine artery systolic/diastolic ratios to change more than the contralateral ratios in hypertensive pregnancies. This may explain the reduced trophoblastic invasion in laterally situated placenta when the uteroplacental blood flow need is mainly met by one side uterine artery. In our study, about 59\% of preeclampsia patients had unilateral location of placenta.

\section{CONCLUSION}

In case of unilateral placenta, the absence or insufficient trophoblastic invasion of arteries on contralateral side would make them retain their sensitivity to vasoactive substance during pregnancy.11,12 Ultrasonography is a simple, noninvasive, easy to perform, cost effective, diagnostic method to identify high risk cases. After identifying such patients, appropriate treatment can be initiated with regular followups.

\section{REFERENCES}

[1] Perloff D. Hypertension and pregnancy related hypertension. Cardiol Clin of N Am 1998;16(1):79-101.

[2] Robert HD, Roberta AD. Ultrasound of the placenta and umbilical cord. In: Callen PW, ed. Ultrasonography in obstetrics and gynaecology. $4^{\text {th }}$ edn. Philadelphia: WB Saunders 2000:p. 597.

[3] Fleischer A, Schulman H, Farmakides G, et al. Uterine artery Doppler velocimetry in pregnant women with hypertension. Am J Obstet Gynaecol 1986;154(4):80613.
[4] Wilson ML, Goodwin TM, Pan VL, et al. Molecular epidemiology of preeclampsia. Obstetrics and Gynaecology Survey 2003;58(1):39-65.

[5] van Beek E, Peeters LL. Pathogenesis of preeclampsia: a comprehensive model. Obstetrics and Gynaecology Survey 1998;53(4):233-9.

[6] Dekker GA, Sibai BM. Etiology and pathogenesis of preeclampsia. Current Concepts Am J Obstetgynaecol 1998;179(5):1359-75.

[7] Kofinas AD, Penry M, Swain M, et al. The effect of placental location on uterine artery flow velocity wave forms. Am J Obstet Gynaecol 1988;159(6):1504-8.

[8] Ito Y, Shono M, Uchiyama A, et al. Resistance index of uterine artery and placental location in intrauterine growth retardation. Acta Obst Gynaecol Scand 1998;77(4):385-90.

[9] Walker JJ. Current thoughts on pathophysiology of preeclampsia/eclampsia. In: Stud J, ed. Progress in obstetrics and gynaecology. Edinburg: Churchill Livingstone 1998:177-188.

[10] Roberts JM, Hubel CA. Is oxidative stress the link in the two-stage model of pre-eclampsia. Lancet 1999;354(9181):788-9.

[11] Pai MV, Pillai J. Placental laterality by ultrasound- a simple yet reliable predictive test for preeclampsia. J Obstet Gynaecolol India 2005;55(5):431-433.

[12] Magann EF, Doherty DA, Turner K, et al. Second trimester placental location as a predictor of an adverse pregnancy outcome. J Perinatol 2007;27(1):9-14. 